\title{
A heat-health watch and warning system with extended season and evolving thresholds
}

\author{
Mahamat Abdelkerim Issa ${ }^{1 *}\left(\mathbb{D}\right.$, Fateh Chebana', Pierre Masselot ${ }^{1}$, Céline Campagna ${ }^{1,2}$, Éric Lavigne ${ }^{3}$, \\ Pierre Gosselin ${ }^{1,2}$ and Taha B. M. J. Ouarda
}

\begin{abstract}
Background: Many countries have developed heat-health watch and warning systems (HHWWS) or early-warning systems to mitigate the health consequences of extreme heat events. HHWWS usually focuses on the four hottest months of the year and imposes the same threshold over these months. However, according to climate projections, the warm season is expected to extend and/or shift. Some studies demonstrated that health impacts of heat waves are more severe when the human body is not acclimatized to the heat. In order to adapt those systems to potential heat waves occurring outside the hottest months of the season, this study proposes specific health-based monthly heat indicators and thresholds over an extended season from April to October in the northern hemisphere.
\end{abstract}

Methods: The proposed approach, an adoption and extension of the HHWWS methodology currently implemented in Quebec (Canada). The latter is developed and applied to the Greater Montreal area (current population 4.3 million) based on historical health and meteorological data over the years. This approach consists of determining excess mortality episodes and then choosing monthly indicators and thresholds that may involve excess mortality.

Results: We obtain thresholds for the maximum and minimum temperature couple (in ${ }^{\circ} \mathrm{C}$ ) that range from (respectively, 23 and 12) in April, to (32 and 21) in July and back to (25 and 13) in October. The resulting HHWWS is flexible, with health-related thresholds taking into account the seasonality and the monthly variability of temperatures over an extended summer season.

Conclusions: This adaptive and more realistic system has the potential to prevent, by data-driven health alerts, heat-related mortality outside the typical July-August months of heat waves. The proposed methodology is general and can be applied to other regions and situations based on their characteristics.

Keywords: Warning systems, Heat wave, Seasonality, Health, Climate, Thresholds, Methods, Mortality

\footnotetext{
* Correspondence: Mahamat_Abdelkerim.Issa@inrs.ca

${ }^{1}$ Centre Eau-Terre-Environnement, Institut National de la Recherche Scientifique, Québec City, Canada

Full list of author information is available at the end of the article
}

(c) The Author(s). 2021 Open Access This article is licensed under a Creative Commons Attribution 4.0 International License, which permits use, sharing, adaptation, distribution and reproduction in any medium or format, as long as you give appropriate credit to the original author(s) and the source, provide a link to the Creative Commons licence, and indicate if changes were made. The images or other third party material in this article are included in the article's Creative Commons licence, unless indicated otherwise in a credit line to the material. If material is not included in the article's Creative Commons licence and your intended use is not permitted by statutory regulation or exceeds the permitted use, you will need to obtain permission directly from the copyright holder. To view a copy of this licence, visit http://creativecommons.org/licenses/by/4.0/. The Creative Commons Public Domain Dedication waiver (http://creativecommons.org/publicdomain/zero/1.0/) applies to the data made available in this article, unless otherwise stated in a credit line to the data. 


\section{Background}

Heat waves are considered among the deadliest extreme weather events worldwide (e.g. [1]). A significant number of deadly heat waves has been observed over the last three decades. The ones of Chicago and Pakistan in July 1995 generated a mortality toll estimated respectively at 670 and 523 deaths $[2,3]$. One of the most famed heat waves was observed in several European countries in August 2003, causing an excess estimated at 45,000 deaths in 12 countries [4]. In July 2010 in Russia, the heat waves increased the number of death by 11,000 more than the previous year [5, 6]. In Quebec, during the five-day heat wave of July 2010, the excess daily mortality reached around 33\% in the Greater Montreal area and four other public health regions [7]. In early July 2018, a six-day heat wave caused $30 \%$ excess mortality in the same geographical region and $23 \%$ excess ambulance transportation [8].

The increase in the number and severity of heat wave events led several countries to establish heat-health watch and warning systems (HHWWS) or early warning systems [9]. These systems are usually based on meteorological indicators (generally maximum, minimum, or mean temperatures, and in some cases the humidity level) or on air masses (in case of the synoptic systems [10]), and a threshold above which a significant increase in mortality is expected [2,11-14]. As in the case of the definition of heat waves, there is no universal threshold for warning systems. This is due to the fact that they reflect local weather/climate conditions and specificities of the local population [2, 15-19]. Moreover, many of these thresholds are still not evidence-based on human heatrelated health mortality or morbidity data [2]. In addition, almost all the existing HHWWSs are established with a single constant threshold for the whole summer season, usually the four or five hottest months $[9,12,20-24]$. The system in Spain is an exception with thresholds that vary in time throughout the year [9]. On the other hand, according to climate projections and due to climate change, the probability of heat waves occurring early or late in the season should increase [25-31]. Ouarda and Charron [32] studied over 50 years of heat waves in six stations across the Province of Quebec. They found a non-negligible increasing trend of the intensity, magnitude, and duration of these events. Another study reported that the number of heat-wave days could increase by up to 13 days in the period 2021 to 2050 and even by up to 40 days in the period 2071 to 2100 in the Iberian Peninsula and the Mediterranean region [33]. Acclimatization is an essential element of the human adaptation mechanism to variations in environmental heat exposure. Several studies have shown that the level of human heat acclimatization varies throughout the season, explaining why deadlier heat waves are often detected in June or July [34-39]. For instance, Lee et al. [35] have demonstrated that, over 148 cities in the U.S., heat effects of increased temperatures were larger in the spring and early summer. It is thus of public health importance to take into account human acclimatization through seasons and develop an early warning system where health-based thresholds could evolve over time, with a monthly resolution, for instance.

In Quebec, The HHWWS proposed by Chebana et al. [12] is already implemented and integrated into public health practice in the province of Quebec. Indeed, the results of this HHWWS constitutes the basis of the automated System for Surveillance and Prevention of the Health Impacts of Extreme Weather Events (Système de surveillance et de prévention des impacts sanitaires des événements météorologiques extremes, SUPREME) [40]. The latter is a source of information allowing regional and departmental stakeholders in the public health network to have access to health and meteorological information relating to the health impacts of extreme weather events.

The objective of the present study is to establish an extended data-driven HHWWS that evolve over the season, based on each month's meteorological and health data (April to October in the studied case). To this end, In the available systems, including but not limited to Chebana et al. [12], the thresholds of the climate variables are constant (the same value) over the whole season. In the present paper, the thresholds are considered not constant but evolving from month to month (each month has its own threshold) within the summer season. In addition, the proposed system is established over a time period beyond the usual hottest summer months in an extended season. Therefore, the proposed system is more realistic since it reflects the climate variability over the season, accounts for early and late heat waves as well as the population adaptation throughout the season. The purpose is to anticipate earlier, longer and hotter summers in the coming decades for the northern countries such as Canada [41].

\section{Data and methods \\ Data}

The data used to establish indicators and thresholds include all-cause daily deaths and meteorological data from the Greater Montreal area, Canada (including public health regions of Montréal, Laval, Lanaudière, Laurentides, and Montéregie; Fig. 1). Health data are available from 1981 to 2015, for a total of 35 years of observations, and are provided by the National Institute of Public Health of Quebec (Institut National de Santé Publique du Québec, INSPQ). The study period is restricted to the months of April to October included. 


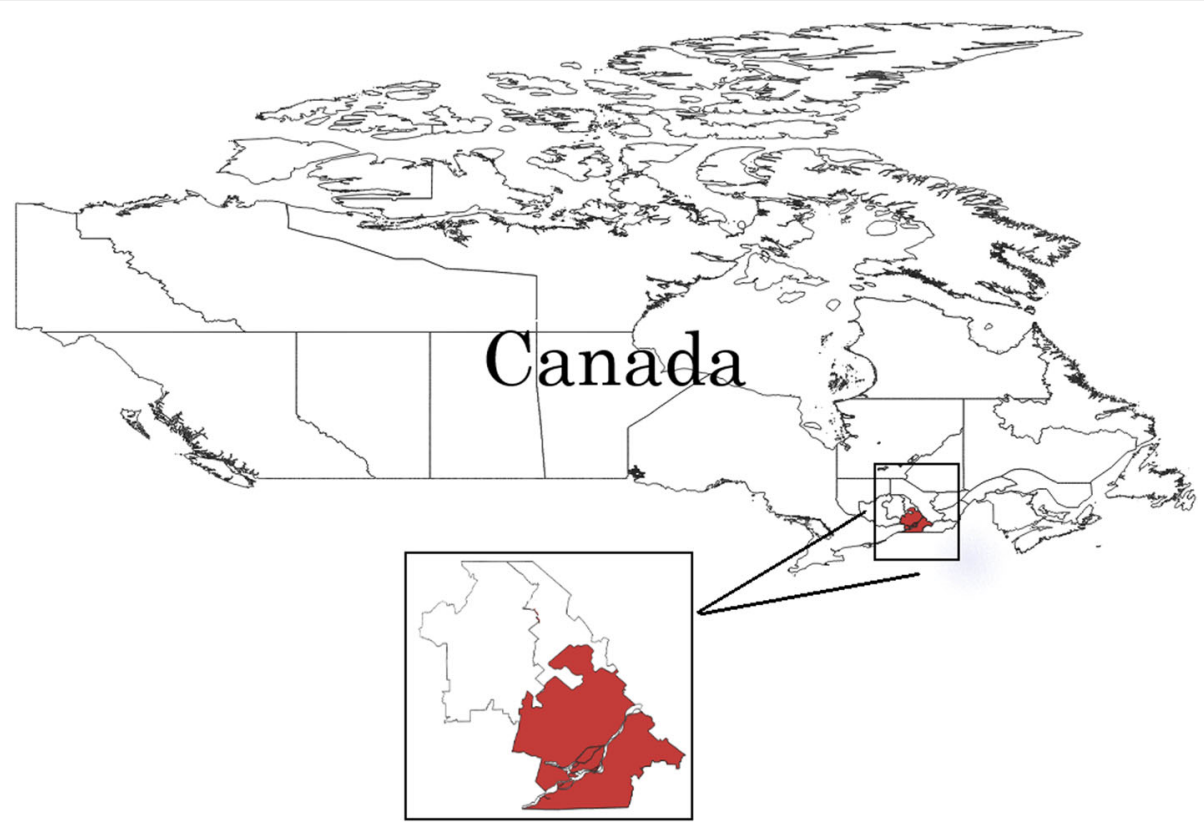

Fig. 1 Study Area, Greater Montreal area, the area is identified with the color red

The meteorological data were available for the same period. Daily maximum and minimum temperatures (noted respectively Tmax and Tmin) are used. They are collected from the DayMet database supported by the National Aeronautics and Space Administration (NASA) [42]. It produces estimates of several daily weather variables on a $1 \mathrm{~km} \times 1 \mathrm{~km}$ gridded surface. Thus, the final temperature series are daily averages over the geographic space of all grid points inside the Greater Montreal area.

\section{Methodology}

Briefly, the purpose of this method is to estimate two indicators $I_{m, t}^{(\operatorname{Tmax})}$ and $I_{m, t}^{(\text {Tmin })}$ for given month $m$ and day $t$, as weighted averages of the associated variable over a number of days (lag), as well as their associated thresholds ( ${ }^{\text {Tmax }}$ and $\mathrm{S}^{\text {Tmin }}$ ) such that $I_{m, t}^{(\text {Tmax })}>\mathrm{S}^{\text {Tmax }} \& I_{m, t}^{(\text {Tmin })}>\mathrm{S}^{\text {Tmin }}$.

The proposed methodology is adapted from previous work by [12], with a number of improvements. The time scale is monthly, and the study period covers April to October. Temperature thresholds of Tmax and Tmin were explicitly modulated to the climate data of each month. This study period considers the human non-acclimation as potential heat waves that could occur in these intermediate and transition periods (late spring or early fall) [36]. Moreover, a rule to determine the preliminary threshold based on the heat wave characteristics was introduced to distinguish heat-related mortality episodes from artifacts. Splines and distributed lag non-linear model (DLNM) were also applied to calculate the expected excess mortality as well as the lags (between the heat wave and the impact on mortality), respectively, as in [43-45]. The method includes four steps as detailed below:

a) Compute excess mortality (EM) relatively to a baseline;

b) Identify heat-related excess mortality episodes;

c) Select the maximum lags for the indicators;

d) Choose the optimal thresholds and associated indicators.

First, we proceed to the division of the database into monthly. Then, the previous steps are applied to each month considered independently. Note that each month is treated alone to obtain specific monthly thresholds. However, the final proposed system is a unique system for the whole period, including all the months. Hence, the performance evaluation was assessed for the system as a whole making the connection between the months. Note that, historical heat waves (i.e. involving public health interventions) were not excluded from the analysis since they are not outliers or errors. In addition, the method discriminates conditions leading to high excess-mortality levels compared to business-as-usual conditions. As the method seeks a binary threshold (either dangerous or not), and not an association (e.g. as in epidemiological studies), a single heat wave cannot dominate the results.

\section{Excess mortality computation}

Excess mortality is defined as the relative difference between observed deaths and the baseline of expected deaths over a period of time $[43,46]$ : 


$$
E M_{t}=\frac{O D_{t}-E D_{t}}{E D_{t}} * 100
$$

where $O D_{t}$ is the number of observed deaths and $E D_{t}$ is the estimated number of expected deaths on day $t$. The approach used here is the same as in [43] where the expected death is calculated by natural cubic splines with eight degrees of freedom per year for a total of 35 years. Note that the degree of freedom value is for the whole year, in order to account for the trend before the computation of EM for each month. Considering splines allows for a more flexible representation of seasonal variations and the long-term mortality trend [43, 47]. The latter gave satisfactory results as shown in Fig. 2 in the results section below.

\section{Identification of heat-related excess mortality episodes}

Once $E M_{t}$ is computed, the following step is to determine EM episodes, i.e., successive days that should be detected by the warning system. These days are those for which the EM value exceeds a predefined mortality threshold (noted $\mathrm{S}_{\mathrm{EM}}$ ). $\mathrm{S}_{\mathrm{EM}}$ is chosen through careful examination of the curve of extreme values of $E M_{t}$ compared to that of total values of $E M_{t}$ as in [43]. Besides, Tmax and Tmin of the same day have to be above preliminary temperature thresholds. This last condition ensures that the identified episode is likely heat-related (since the EM episode corresponds to the $T$ episode). In the present study, preliminarily temperatures considered were: the 90th percentile for April, 95th for May, 92.5th for June-August, 95th for September, and 92.5th for October, corresponding to the range of percentiles in the literature for the definition of a heat wave [48-50]. The selection of these percentiles is based on computing the associated number of heat waves that should have occurred and choosing the value of the different percentiles cited above as thresholds in applying the heat wave definition. The choice of these percentile to determine the preliminary temperature is based on the relative minimum number of heat waves that could possibly be generated by the preliminary temperature. This allows us to distinguish heat-related mortality episodes from artifacts and not to put all months on the same level; because they do not have the same weather reality or characteristic. Chiu, Y. et al. [51] indicated that the extreme peaks tend to occur in clusters. Therefore, we combine consecutive EM exceedance days into one episode. In the present study, two EM peaks or "episodes" separated by less than three days are considered as a single episode (here, a heat wave).

\section{Selection of the maximum lags for temperature indicators}

The indicator used in the HHWWS consists of a weighted mean/average of lagged temperature over a number of days. Using lagged temperature allows taking into account the effect that could occur after the hot day. It is denoted by $I_{m, t}^{(k)}$ for all $k \in\{\operatorname{Tmax}, \operatorname{Tmin}\}$, and is defined as follows:

$$
I_{m, t}^{(k)}=\sum_{j=0}^{l} a_{j\lrcorner k} X_{m, t-j}^{(k)}
$$

where $X_{m, t-j}^{(k)}$ are the values of the daily temperature

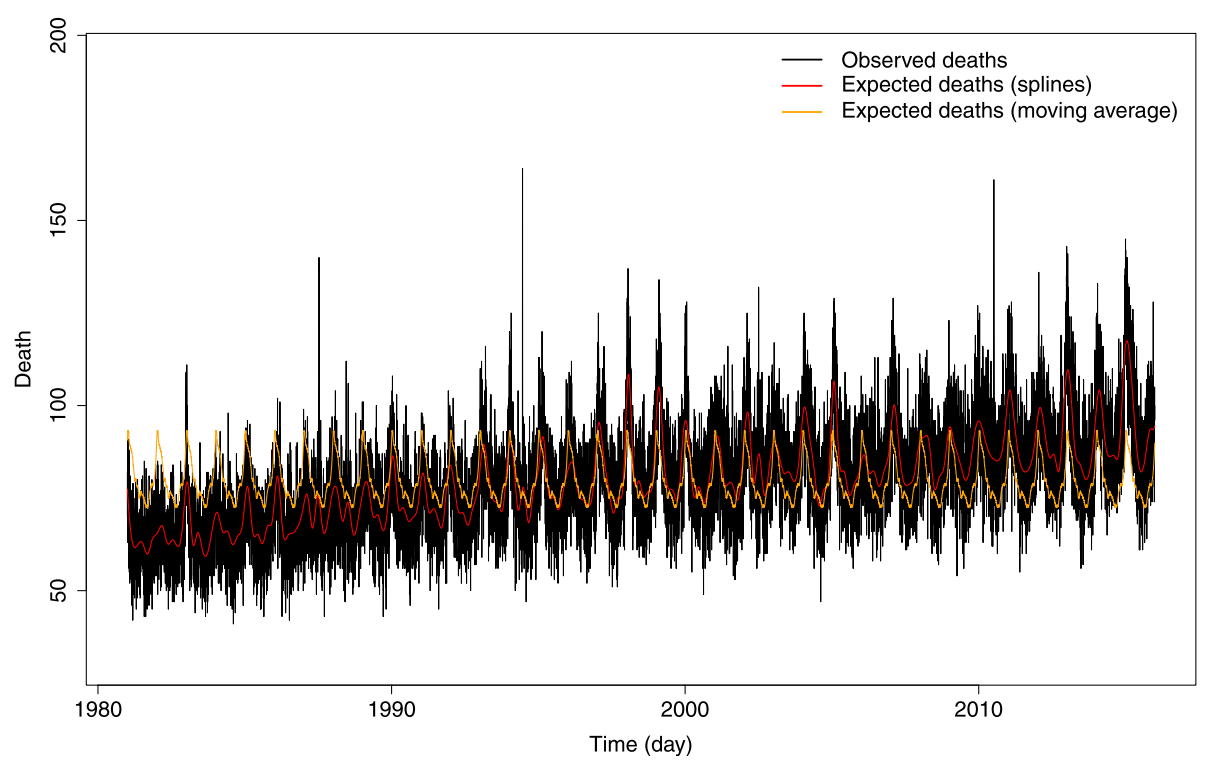

Fig. 2 Daily observed Mortaility with the expected death estimate using the moving average (orange) and splines (red) for data from May to October 
(Tmax or Tmin, in the present case) for month $m$ and lagged at day $t$ minus the associated lag $j$, and the coefficients $\alpha_{j k k}$ are the weights such that $\alpha_{0 k k} \geq \alpha_{1 k k} \geq \cdots \geq \alpha_{l k k}$ (condition 1) and $\Sigma_{j} \alpha_{j \_k}=1$ (condition 2). The first condition ensures that the weights assigned to each day decreases with the time horizon, ensuring that the system, once implemented, will account for the decreasing accuracy of temperature forecasts with the horizon (e.g. [52]). The role of the second condition is to ensure the indicators to be on the same scale as their respective temperature variables.

The purpose of the present step consists of determining the maximum lag $l$ of indicators in eq. (2). This is chosen by examining the lag response relationship between extreme temperature and mortality estimated using a DLNM [53]. The temperature dimensions of the DLNM surface are modeled through a penalized spline whereas the lag dimension through a natural spline with three knots [54]. Unmeasured confounders are included as a natural spline of time with four degrees of freedom for the day of the season and one degree of freedom per decade for interannual trends [55]. The used measured confounder is relative humidity. A quasi-Poisson family is used to account for over-dispersion, as in $[53,56]$.

\section{Selection of the best health-based temperature thresholds and associated indicators}

The objective of this final step is to determine the optimal thresholds $\mathrm{S}^{\text {Tmax }}$ and $\mathrm{S}^{\text {Tmin }}$, as well as indicator weights $\alpha_{j_{-} k}$. They are chosen based on comparing detected alerts (modeled episodes) and actual EM episodes. Thus, for given weights and threshold values, the estimated heat waves episodes are such that $I_{m . t}^{(\operatorname{Tmax})}>\mathrm{S}^{\text {Tmax }}$ $\& I_{m, t}^{(\text {Tmin })}>\mathrm{S}^{\text {Tmin }}$.

As in [12], the quality of each (weights, thresholds) combination is assessed using the following criteria: i) sensitivity, which is the probability of detections being actual EM episodes; ii) number of false alerts (FA), which are estimated as EM that are not actual EM episodes. The best-modeled system is the one with high sensitivity and the minimum FA.

\section{Results}

In this section, we present the obtained results for the Greater Montreal area data, and then we consider a sensitivity analysis.

\section{Results of the proposed methodology}

The following results are obtained by following the above four steps of the presented methodology.

\section{Excess mortality}

Step 1 of the methodology seeks to estimate EM as a function of the expected deaths through eq. (1). Figure 2 shows the interest in using the spline approach to quantify the expected deaths. Descriptive statistics of the estimated daily excess mortality are presented in Table 1.

The results in Table 1 indicate that months belonging to the Cool period (April, May, September and October) have roughly the same standard deviation of EM which are relatively lower than those of summer months (June, July, August). This more important standard deviation of the summer months is probably related to the important EM maxima witnessed during this period (e.g. historical deadly heat waves). As for the summer season, June recorded the highest EM value (111.2\%). It even exceeded that of the heat wave period of July 2010 (88.3\%, which corresponds to the maximum for July).

\section{Heat-related excess mortality episodes}

Before identifying the episodes, the aim here is to choose the EM threshold $S_{\mathrm{EM}}$ above which a day is included within an episode. Figure 3 shows the number of EM episodes obtained for different $S_{\mathrm{EM}}$ values for each month. Regarding April and May, Fig. 3a shows that for values of $\mathrm{S}_{\mathrm{EM}}$ higher than $35 \%$, the number of heat-related $\mathrm{EM}$ episodes and the total number (unconstrained) of episodes are equal to zero for both months. Thus, we consider respectively the $\mathrm{S}_{\mathrm{EM}}$ equal to 10 and $30 \%$ as $\mathrm{EM}$ thresholds of April and May, which corresponds to one episode for each one. Figure $3 \mathrm{~b}$ indicates that the EM episodes associated with threshold values above $45 \%$ are almost all related to heat for July. Hence, we choose $\mathrm{S}_{\mathrm{EM}}=50 \%$ for June, and $\mathrm{S}_{\mathrm{EM}}=40 \%$ for July and August with one, four and one episodes respectively. For the last months, in Fig. 3c, the outcomes are similar to the results of those in Fig. 3a. Then, we choose the values of 30 and $10 \%$ as preliminary thresholds for September and October, which corresponds to two and one episodes, respectively.

Figure 4 shows the computed EM series along with the EM episodes identified through the $S_{\mathrm{EM}}$ thresholds

Table 1 Descriptive statistics and standard deviation of the estimated daily excess mortality for the different months throughout the study period (\%)

\begin{tabular}{lllll}
\hline Month & Minimum & Mean & Maximum & Standard deviation \\
\hline April & -38.1 & 0.4 & 44.8 & 11.7 \\
May & -35.1 & -0.1 & 40.3 & 12.2 \\
June & -33.8 & 0.2 & 111.2 & 13.4 \\
July & -35.7 & 0.6 & 88.3 & 14.2 \\
August & -36.3 & -1.0 & 40.9 & 12.3 \\
September & -35.1 & -0.5 & 40.9 & 12.1 \\
October & -34.3 & 2.2 & 48.9 & 11.8 \\
\hline
\end{tabular}




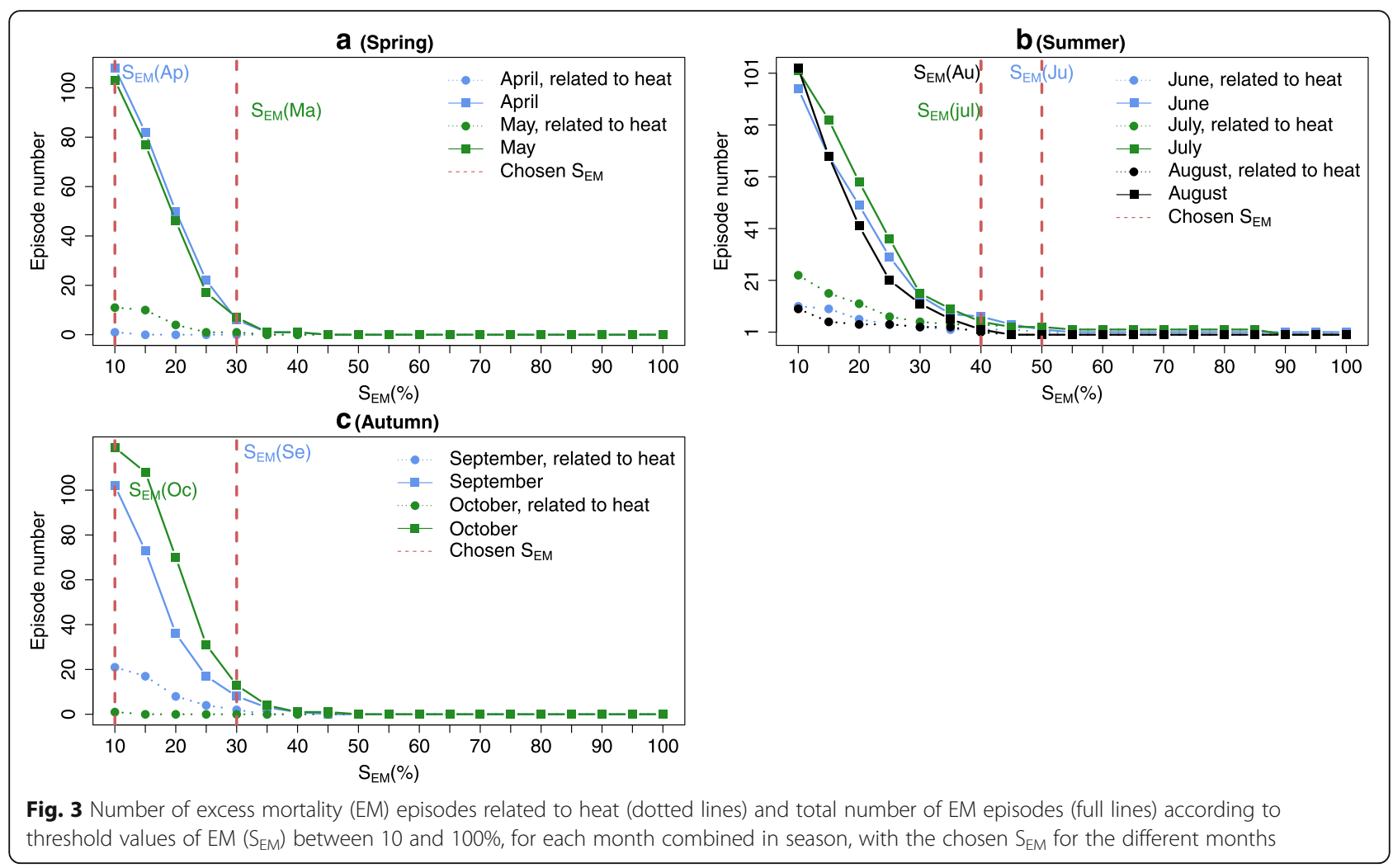

obtained in the previous step. The highest number of EM episodes is observed in July (four EM episodes), followed by September (two EM episodes) and the lowest is recorded during all other months (four EM episodes).

\section{Selection of lags for the indicators}

Figure 5 shows slices of the DLNM surface at each preliminary temperature threshold determined in section 2.2. For spring months, Fig. 5a shows that Relative risk (RR) is significantly higher than 1 only for lags 0 and 1 for May. In April, the RR trend is different with a negative association for the smallest lags, probably due to late cold days. We therefore choose $l=1$ for the Tmax indicator in both April and May. Regarding Tmin, Fig. 5b illustrates that the lag-response relationship for May reaches its highest $R R$ for lag 0 and then remains stable around 1 (respectively the lag 1 for April). Regarding the maximum lag for the Tmin indicator is then chosen at $l=1$ for both May and April. For Tmax, Fig. 5c shows that the RRs for all summer months are strongly significant with a lag 0 , but remain significant at lag 1 . We observe the same thing at lag 0 and at lag 1 the RR stays around 1 for Tmin (Fig. 5d). Thus, we choose an indicator based on lag 1 for Tmax and Tmin of all summer months. For Autumn months, Fig. 5e suggests for Tmax a lag 0 with RR values significantly higher than 1 for September and then decreases to 1 , but it is non- negligible at lag 1. RR for Tmax corresponding to October is consistently around 1 for all lags. Although the RR of Tmin (Fig. 5f) for the two months are close to 1 for lags 1 , we choose a lag value equal to 1 for the Tmax and Tmin.

\section{Thresholds and indicators of the system}

Table 2 summarizes the results related to the different months corresponding to the chosen temperature thresholds and indicator weights. It shows that the Tmax indicator weights are mainly assigned to the first day of all months except for May, June, and August. For Tmin, weights are based on two days. As expected, temperature thresholds increase up to July and decrease afterward. The performance criteria indicate that the resulting system has a sensitivity of $100 \%$ and less than one false alert per year. These performance results are almost similar to those of the current system, which corresponds to class 1 in [12]. As indicated in the methodology, the corresponding values of performance criteria (sensitivity and false alert) are per month, but for the whole system. Finally, Fig. 6 illustrates the obtained results in terms of thresholds, lags, and weights for each month.

\section{Sensitivity analysis}

The selected lags to identify the final temperature thresholds are mainly based on the estimated lagresponse relationship of the DLNM. Besides, the weights 


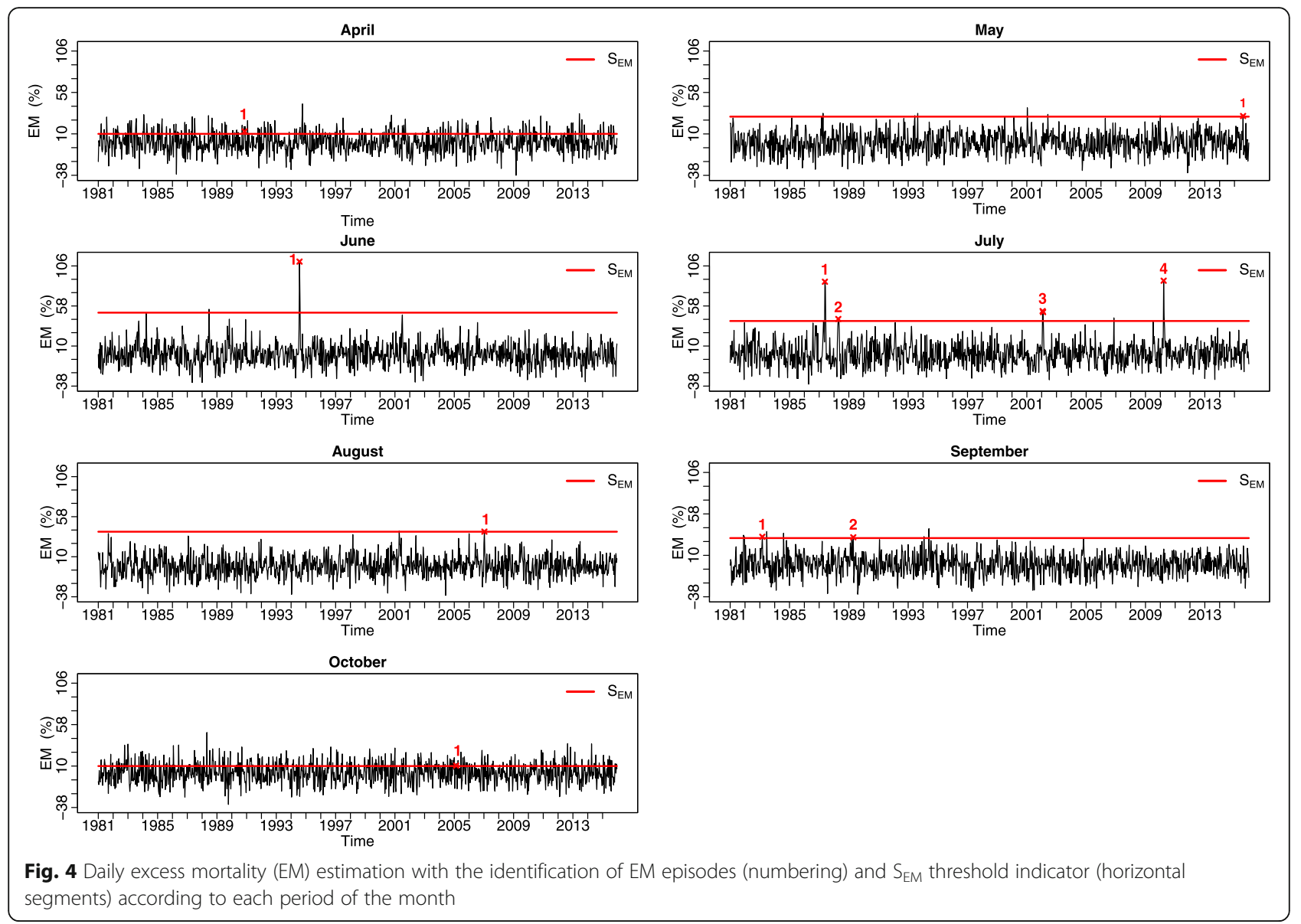

are constrained. Even though these choices lead to high performances, a sensitivity analysis of the system performances is hereby performed regarding the two factors (lag and weights). In particular, sensitivity to the choice of lag is evaluated by running the methodology using lag 2 (three days), as was the case in previous studies [12, 57]. Figure 7 shows the receiver operating characteristic (ROC) curve that relates the sensitivity of the HHWWS to its number of false episodes per year, for each of the following designs. The first case is the system with lag equal to 1 and with the weighting constrained to be the same for both indicators. The second case uses a lag 2 with different weights. Finally, the third case also uses lag 2, but with the same weights. Note that the ideal ROC curve is the one that passes through the upper left corner of sensitivity $=1$ and false episode $=0$.

Figure 7 indicates that the performance of the HHWWS is lower using $l=1$ (case 1 ) with equal weights for both indicators compared to the cases with $l=2$ (cases 2 and 3). In case 2, HHWWS shows a ROC curve close to the upper left corner. However, it remains less performant when compared to the obtained system in terms of the number of false episodes. This is consistent with the results shown in Fig. 5 in which $l=1$ is the significant lag compared to $l=2$. Therefore, the choice of a system with $l=1$ and different indicator weights is optimal.

\section{Discussion}

This study proposes for the first time a data-based HHWWS that can adapt the mortality-related temperature thresholds to the months (instead of a whole season) and heat wave detection over an extended season based on the characteristics of each month, especially with adaptive and evolving threshold. To carry out our study, we used health data of all-cause mortalities without distinguishing the cause of deaths. Indeed, both all-cause and non-accidental deaths were studied with slight different results between the two cases in a previous study [12]. Besides, considering all data, allows us to have relevant/credible thresholds. The scientific literature on this aspect has focused on the summer season and often more specifically on the hottest four months of the year [48]. Most authors use a single threshold for the whole summer season and with an excess mortality threshold at $60 \%[9,12,20,21]$. 


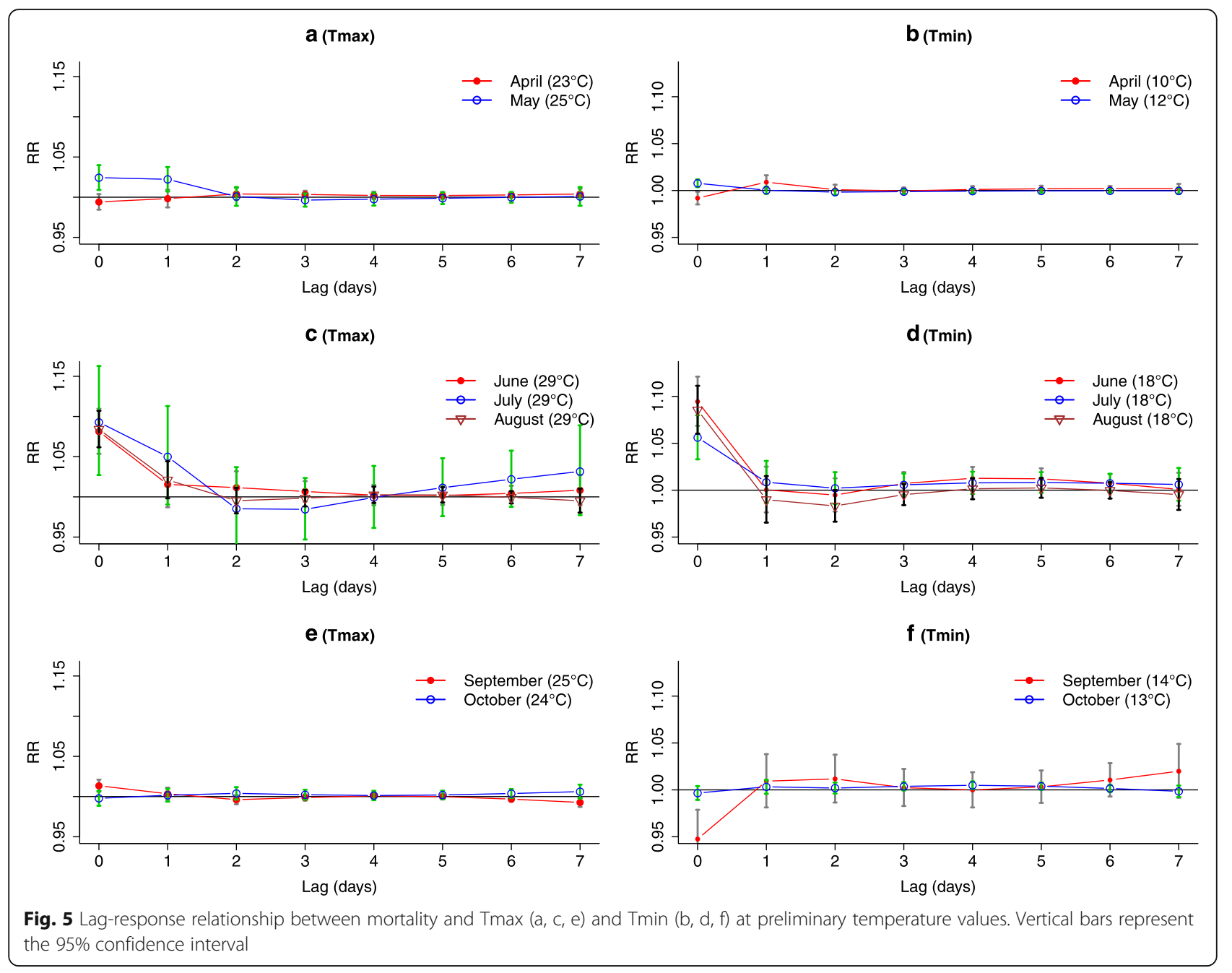

The proposed approach for defining these thresholds is an adaptation of the approach currently used in Quebec [12], especially the evolving aspect of the threshold. In addition, improvements include the determination of a rule to filter out potential deaths related to heat, the formulation of the indicator, and the determination of lags to be considered in the construction of the indicators.

It should be noted that among the four EM episodes in July, we found two that were detected in the study of [58]. One among the EM episodes is related to the 2010 heat wave that occurred in Quebec. This could confirm

Table 2 Indicator weights, thresholds, EM thresholds, sensitivity and number of false alert (FA) per year for the various months

\begin{tabular}{|c|c|c|c|c|c|c|c|c|c|}
\hline \multirow[t]{2}{*}{ Month } & \multicolumn{4}{|c|}{ Indicator weights } & \multicolumn{2}{|c|}{ Thresholds $\left({ }^{\circ} \mathrm{C}\right)$} & \multirow[t]{2}{*}{$\mathrm{S}_{\mathrm{EM}}(\%)$} & \multirow[t]{2}{*}{ Sensitivity(\%) } & \multirow[t]{2}{*}{ FA/year } \\
\hline & $\overline{a_{0 \_} \max }$ & $\mathbf{a}_{1 \_ \text {Imax }}$ & $a_{0 \_ \text {Imin }}$ & $\overline{a_{1 \_T \min }}$ & $S^{T \max }$ & $S^{T \min }$ & & & \\
\hline April & 1.0 & 0.0 & 0.8 & 0.2 & 23 & 12 & 10 & 100.0 & 0.1 \\
\hline May & 0.5 & 0.5 & 1.0 & 0.0 & 27 & 13 & 30 & & \\
\hline June & 0.8 & 0.2 & 0.6 & 0.4 & 32 & 20 & 50 & & \\
\hline July & 1.0 & 0.0 & 0.7 & 0.3 & 32 & 21 & 40 & & \\
\hline August & 0.6 & 0.4 & 0.5 & 0.5 & 31 & 19 & 40 & & \\
\hline September & 1.0 & 0.0 & 0.6 & 0.4 & 28 & 19 & 30 & & \\
\hline October & 1.0 & 0.0 & 1.0 & 0.0 & 25 & 13 & 10 & & \\
\hline
\end{tabular}




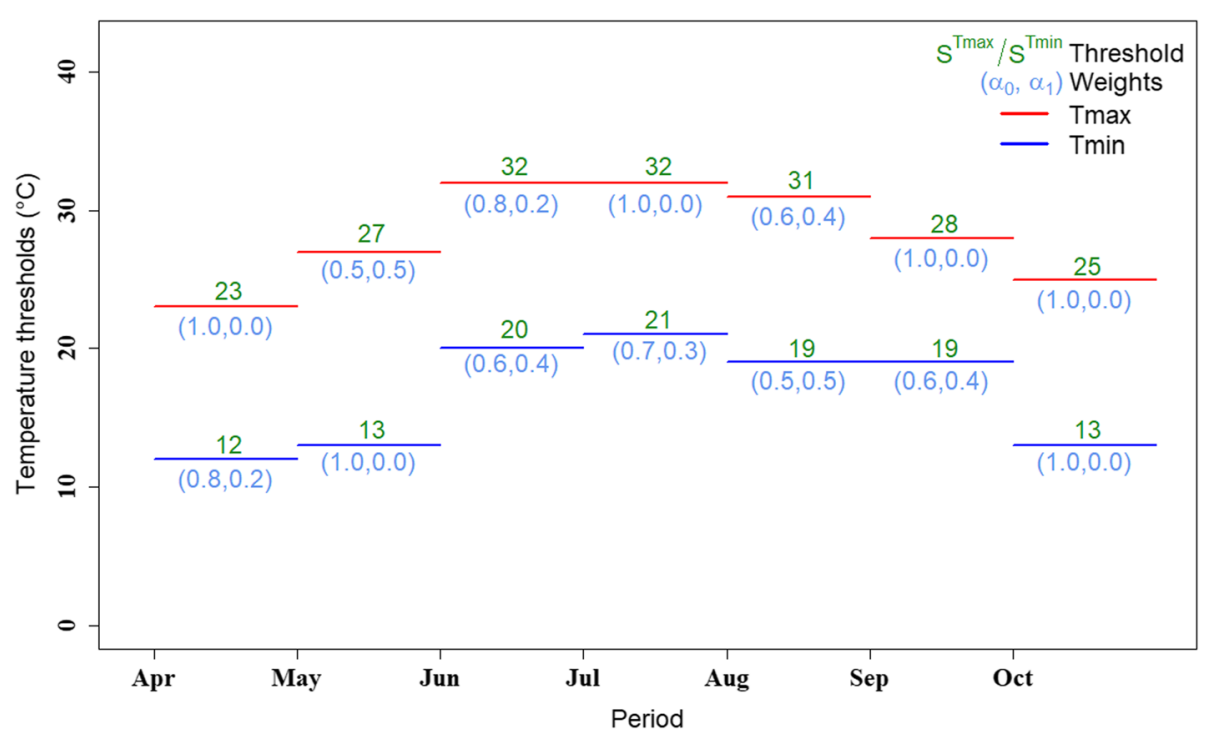

Fig. 6 Final recommended thresholds per month and lag is always 2 except when a2 is equal to zero lag becomes 1

that the choice of the monthly resolution also allows for a good characterization of the heat wave following each specific period. As a result, the system can distinguish between true positive and false positive. Previously published health-related heat thresholds $[12,58]$ for the same geographical area (Greater Montreal area) is shown in Table 3 in order to compare them with the present results (Table 2). Having split the system in monthly intervals did not shown aberrant results compared to a system taking into account the hole extended summer. The threshold values of Tmax and Tmin obtained in the present study applied to months April-October varies from 23 to 32 for Tmax and from 12 to 21 for Tmin. The average Tmin threshold for the summer months is similar to the one currently used by the national HHWWS in the same area of interest (Table 3). The one of Tmax has a difference of $1{ }^{\circ} \mathrm{C}$. Nevertheless, they have almost the same performances.

Figure 8 illustrates the thresholds of the current and previous studies. We note that the Tmax threshold of June coincides with that of July and idem between $\mathrm{Au}$ gust and September for the Tmin thresholds. This can

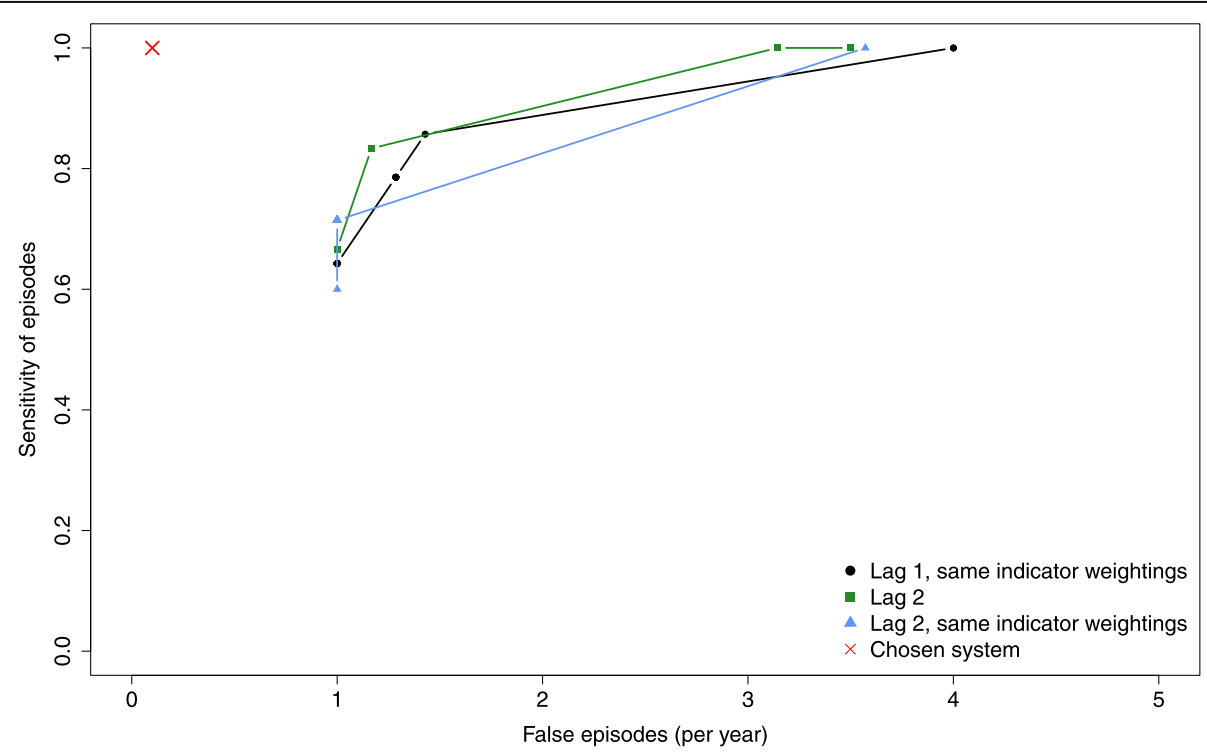

Fig. 7 Receiver operating characteristic (ROC) curves for different lag values used to develop the HHWWS, with the red cross represents the resulting system 
Table 3 Indicator weights, thresholds currently in use, and the present study in the Greater Montreal area

\begin{tabular}{|c|c|c|c|c|c|c|c|c|c|c|c|}
\hline \multirow[t]{2}{*}{ Geographical area } & \multirow[t]{2}{*}{ Season } & \multirow[t]{2}{*}{ Lag } & \multicolumn{5}{|c|}{ Indicator weights } & \multicolumn{2}{|c|}{ Thresholds $\left({ }^{\circ} \mathrm{C}\right)$} & \multicolumn{2}{|c|}{ Performance results } \\
\hline & & & $\overline{a_{0}}$ & & $a_{1}$ & & $\overline{a_{2}}$ & $s^{\operatorname{Tmax}}$ & $\mathrm{s}^{T \min }$ & Sensitivity (\%) & FA/year \\
\hline $\begin{array}{l}\text { Greater Montreal area }{ }^{2} \\
{[12]}\end{array}$ & May-September & 2 & 0.4 & & 0.4 & & 0.2 & 33 & 20 & 100 & 0.12 \\
\hline The present study (median result) & May-September & 1 & 0.8 & $0.7^{*}$ & 0.2 & $0.3^{*}$ & n.a & 32 & 21 & 100 & 0.10 \\
\hline
\end{tabular}

be explained by the border effect between the differences in question.

The present system has some limitations. The proposed approach to establishing an HHWWS with an evolving threshold is still subjective concerning the criterion of determining a threshold for excess mortality, since it is graphically-based. However, the foundation of this step is based on the characteristics of the phenomenon to be studied (heat wave) and its link with the health outcome (mortality). Other points of improvement could concern meteorological indicators (Tmax and Tmin) to be used. It could be interesting to test other indicators such as Wet-Bulb/ WBGT, Excess Heat Indices, UTCI, diurnal temperature range [59-71]. Not considering humidity as meteorological indicator is another limitation of this study. Indeed, humidity is important from a physiological point of view (perceived heat) and therefore might have a role to play in the effects of heat on human health [72-74]. However, the scientific data available are not consistent on a populational basis and are geographically-dependent. Studies have tried to include humidity, humidex, or apparent temperature in modeling for all-cause mortality, and those indicators always ended non-significant $([12,75])$. Hence, the role of humidity on mortality remains unclear (e.g. [75]). In Chebana et al. [12], humidex was used as a validation variable for forecasts. Another point could also be the edge effect, leading to a smooth threshold. This system ought to be updated frequently to ensure the inclusion of taking into account the changing climate variables. We can also see from Fig. 4 with the data available on April and October that it is not obvious to determine the EM threshold. However, this does not have too much influence on the statistical power of the final meteorological thresholds to identify EM for the medium and long term. It is important to mention that cold temperatures have an acute impact on health and mortality. However, heat and cold have different behavior and impacts on health, as well as different confounders should be counted for (e.g. influenza for cold but not for heat). Indeed, Yan et al. [44] focused on developing a cold system applied to the province of Quebec [44] where the temperature thresholds are considered constant over the winter season. Therefore, a similar system with evolving cold temperature thresholds

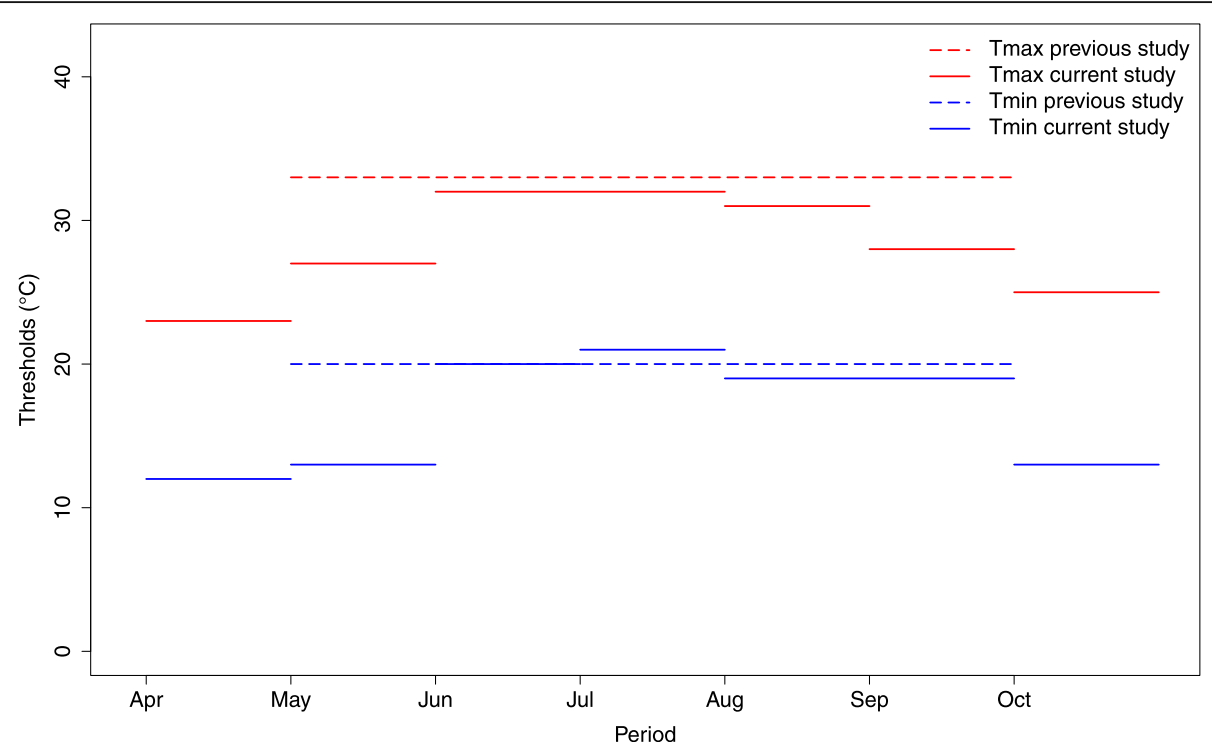

Fig. 8 Thresholds of the previous study for the study area from May to September and the present study thresholds following months April-October 
for winter season is an interesting perspective of the present work.

\section{Conclusions}

In this paper, we developed an HHWWS that has adjusted thresholds for each month, taking into account the human acclimatization through seasons as well as climate variability over the season. In addition, this novel system covers an extended season and can help public health authorities prepare for heat waves, especially in the context of climate change. The proposed methodology is general and can be applied or adapted to other regions.

The proposed methodology consists in determining meteorological threshold values (maximum and minimum temperatures) that could significantly increase mortality through the evaluation of the heat-mortality relation. The thresholds obtained start in April with $23^{\circ} \mathrm{C}$ for Tmax and $12{ }^{\circ} \mathrm{C}$ for Tmin, to reach $32^{\circ} \mathrm{C}$ and $21{ }^{\circ} \mathrm{C}$ in July, then back down to $25^{\circ} \mathrm{C}$ and $13{ }^{\circ} \mathrm{C}$ in October. The final recommended thresholds per month and lags are summarised in Fig. 6. The system could also be improved by considering other health outcomes such as hospital admissions.

\section{Abbreviations}

DLNM: Distributed lag non-linear model; EM: Excess mortality; FA: False alerts; HHWWS: Heat-health watch and warning systems; RR: Relative risk; $\mathrm{S}_{\mathrm{EM}}$ : Predefined exceeds mortality threshold; Tmax: Maximum temperature; Tmin: Minimum temperature; UTCI: Indice universel du climat thermique; WBGT: Wet-bulb globe temperature

\section{Acknowledgments}

The authors would like to thank Christian Filteau and Jean-Xavier Giroux for their support in the extraction of the data used in the study. All analyses are performed in the open source $\mathrm{R}$ software environment. The authors are grateful to the Editor and anonymous reviewers for their comments and suggestions.

\section{Authors' contributions}

MAl: conclusive analysis, methodology, software, writing-original draft, visualization; FC: conceptualization, methodology, writing-review and editing, supervision, funding acquisition; PM.: validation, software, writing-review and editing; CC: conceptualization, validation, writing — review and editing, funding acquisition; ÉL: validation, writing — review and editing; PG: validation, writing — review and editing; TO: writing - review and editing. All authors have read and approved the manuscript.

\section{Funding}

The present study was funded by the Climate Change Action Plan of the Quebec government, in collaboration with the Institut National de Santé Publique du Québec (INSPQ), the Ouranos consortium and MITACS. The funding organization was contributed by two co-investigators and two member of the monitoring committee in study.

\section{Availability of data and materials}

The database of meteorological data is extracted from the DayMet database available at https://daymet.ornl.gov/getdata. The health data were extracted from medicoadministrative databases (mortality files) hosted by the Ministry of Health of Québec. The health data used are not publicly available at this level of granularity.

\section{Declarations}

Ethics approval and consent to participate

Spatially and temporally aggregated meteorological data (number per day over an entire region) are used, so no ethical considerations are needed. For The health data, the study was conducted according to an agreement established between the INSPQ and the government of Quebec as part of the ministerial plan of multithematic health surveillance. This plan has received its ethics approval by the Public Health Ethics Committee in January 2010 (ISBN: 978-2-550-58576-3; https://www.inspq.qc.ca/ publications/1124).

\section{Consent for publication}

Not applicable.

\section{Competing interests}

There are no competing interests to declare.

\section{Author details}

${ }^{1}$ Centre Eau-Terre-Environnement, Institut National de la Recherche Scientifique, Québec City, Canada. ${ }^{2}$ Institut National de Santé Publique du Québec, Québec, Canada. ${ }^{3}$ School of Epidemiology and Public Health, University of Ottawa, Ottawa, Canada.

Received: 24 July 2020 Accepted: 5 May 2021

Published online: 29 July 2021

\section{References}

1. Dousset B, Gourmelon F, Giraudet E, Laaidi K, Zeghnoun A, Bretin P, et al. Evolution climatique et canicule en milieu urbain: apport de la télédétection à l'anticipation et à la gestion de l'impact sanitaire; 2011.

2. $\mathrm{WMO}, \mathrm{W}$, Heat waves and health: guidance on warning-system development. World Meteorological Organization and World Health Organization. http://www.who.int/globalchange/publications/heatwaveshea Ith-guidance/en. Accessed, 2015. 12.

3. Semenza JC, McCullough JE, Flanders WD, McGeehin MA, Lumpkin JR. Excess hospital admissions during the July 1995 heat wave in Chicago. Am J Prev Med. 1999;16(4):269-77.

4. Robine J-M, Cheung SLK, Le Roy S, Van Oyen H, Griffiths C, Michel J-P, et al. Death toll exceeded 70,000 in Europe during the summer of 2003. Comptes Rendus Biologies. 2008;331(2):171-8.

5. Rahmstorf S, Coumou D. Increase of extreme events in a warming world. Proc Natl Acad Sci. 2011:108(44):17905-9.

6. Otto FE, Massey N, Van Oldenborgh G, Jones R, Allen M. Reconciling two approaches to attribution of the 2010 Russian heat wave. Geophys Res Lett. 2012;39(4):1-5.

7. Bustinza R, Lebel G, Gosselin P, Bélanger D, Chebana F. Health impacts of the July 2010 heat wave in Quebec, Canada. BMC Public Health. 2013;13(1): 56.

8. Lebel G, Dubé M, Bustinza R. Surveillance des impacts des vagues de chaleur extrême sur la santé au Québec à l'été 2018; 2019.

9. Casanueva A, Burgstall A, Kotlarski S, Messeri A, Morabito M, Flouris AD, et al. Overview of existing heat-health warning systems in Europe. Int J Environ Res Public Health. 2019:16(15):2657.

10. Sheridan SC, Kalkstein LS. Progress in heat watch-warning system technology. Bull Am Meteorol Soc. 2004:85(12):1931-42.

11. World Health Organization 2009, Improving public health responses to extreme weather/heat-waves- EuroHEAT. Technical summary, 2009.

12. Chebana F, Martel B, Gosselin P, Giroux J-X, Ouarda TB. A general and flexible methodology to define thresholds for heat health watch and warning systems, applied to the province of Québec (Canada). Int J Biometeorol. 2013;57(4):631-44.

13. Hajat S, Sheridan SC, Allen MJ, Pascal M, Laaidi K, Yagouti A, et al. Heathealth warning systems: a comparison of the predictive capacity of different approaches to identifying dangerously hot days. Am J Public Health. 2010 100(6):1137-44.

14. Masato G, Bone A, Charlton-Perez A, Cavany S, Neal R, Dankers R, et al. Improving the health forecasting alert system for cold weather and heatwaves in England: a proof-of-concept using temperature-mortality relationships. PLoS One. 2015;10(10):1-15. 
15. Medina-Ramon M, Schwartz J. Temperature, temperature extremes, and mortality: a study of acclimatisation and effect modification in 50 US cities Occup Environ Med. 2007;64(12):827-33.

16. McMichael AJ, Wilkinson P, Kovats RS, Pattenden S, Hajat S, Armstrong B, et al. International study of temperature, heat and urban mortality: the 'ISOTHURM'project. Int J Epidemiol. 2008;37(5):1121-31.

17. Naumann G, Vargas WM. A study of intraseasonal temperature variability in southeastern South America. J Clim. 2012;25(17):5892-903.

18. Sung T-I, Wu P-C, Lung S-C, Lin C-Y, Chen M-J, Su H-J. Relationship between heat index and mortality of 6 major cities in Taiwan. Sci Total Environ. 2013; 442:275-81.

19. Hémon D, Jougla E. Surmortalité liée à la canicule d'août 2003: rapport d'étape; 2003.

20. Pascal M, Laaidi K, Ledrans M, Baffert E, Caserio-Schönemann C, Le Tertre A, et al. France's heat health watch warning system. Int J Biometeorol. 2006; 50(3):144-53.

21. McLean KE, Stranberg R, MacDonald M, Richardson GR, Kosatsky T, Henderson SB. Establishing heat alert thresholds for the varied climatic regions of British Columbia, Canada. Int J Environ Res Public Health. 2018; 15(9):2048.

22. Nicholls N, Skinner C, Loughnan M, Tapper N. A simple heat alert system for Melbourne, Australia. Int J Biometeorol. 2008;52(5):375-84.

23. Lowe $\mathrm{D}$, Ebi $\mathrm{KL}$, Forsberg B. Heatwave early warning systems and adaptation advice to reduce human health consequences of heatwaves. Int J Environ Res Public Health. 2011;8(12):4623-48.

24. McGregor GR, Bessmoulin P, Ebi K, Menne B. Heatwaves and health: guidance on warning-system development: WMOP; 2015. p. 1-128.

25. Perkins S, Alexander L, Nairn J. Increasing frequency, intensity and duration of observed global heatwaves and warm spells. Geophys Res Lett. 2012; 39(20).

26. IPCC. In: Field CB, Barros V, Stocker TF, Qin D, Dokken DJ, Ebi KL, Mastrandrea MD, Mach KJ, Plattner G-K, Allen SK, Tignor M, Midgley PM, editors. Managing the Risks of Extreme Events and Disasters to Advance Climate Change Adaptation. A Special Report of Working Groups I and II of the Intergovernmental Panel on Climate Change. Cambridge and New York: Cambridge University Press; 2012

27. Patz J, Campbell-Lendrum D, Gibbs H, Woodruff R. Health impact assessment of global climate change: expanding on comparative risk assessment approaches for policy making. Annu Rev Public Health. 2008;29: 27-39.

28. Honda Y, Kondo M, McGregor G, Kim H, Guo Y-L, Hijioka Y, et al. Heatrelated mortality risk model for climate change impact projection. Environ Health Prev Med. 2014;19(1):56-63.

29. Li T, Horton RM, Kinney PL. Projections of seasonal patterns in temperaturerelated deaths for Manhattan, New York. Nat Climate Change. 2013;3(8): 717-21

30. Gosselin P, Bélanger D. Recherche, impacts et adaptations de santé publique au nouveau climat du Québec. Santé Publique. 2010;22(3):291302.

31. Stocker TF, Qin D, Plattner G-K, Tignor M, Allen SK, Boschung J, et al. Climate change 2013: The physical science basis. In: Contribution of working group I to the fifth assessment report of the intergovernmental panel on climate change; 2013. p. 1535.

32. Ouarda TB, Charron C. Nonstationary Temperature-Duration-Frequency curves. Sci Rep. 2018;8(1):1-8.

33. Fischer EM, Schär C. Consistent geographical patterns of changes in highimpact European heatwaves. Nat Geosci. 2010;3(6):398-403.

34. Basu R, Samet JM. Relation between elevated ambient temperature and mortality: a review of the epidemiologic evidence. Epidemiol Rev. 2002; 24(2):190-202.

35. Lee M, Nordio F, Zanobetti A, Kinney P, Vautard R, Schwartz J. Acclimatization across space and time in the effects of temperature on mortality: a time-series analysis. Environ Health. 2014;13(1):89.

36. Gasparrini A, Guo Y, Hashizume M, Lavigne E, Tobias A, Zanobetti A, et al. Changes in susceptibility to heat during the summer: a multicountry analysis. Am J Epidemiol. 2016;183(11):1027-36.

37. Bustinza R, Lebel G, Dubé M. Surveillance des impacts sanitaires des vagues de chaleur extrême au Québec: bilan de la saison estivale 2013; 2014.

38. Hajat S, Kovats RS, Atkinson RW, Haines A. Impact of hot temperatures on death in London: a time series approach. J Epidemiol Community Health. 2002;56(5):367-72.
39. Price K, Perron S, King N. Implementation of the Montreal heat response plan during the 2010 heat wave. Can J Public Health. 2013;104(2):e96-e100.

40. Toutant S, Gosselin P, Bélanger D, Bustinza R, Rivest S. An open source web application for the surveillance and prevention of the impacts on public health of extreme meteorological events: the SUPREME system. Int J Health Geogr. 2011;10(1):39.

41. Zhang X, Flato G, Kirchmeier-Young M, Vincent L, Wan H, Wang X, et al. Changes in temperature and precipitation across Canada. Can Changing Climate Rep. 2019:112-93.

42. Thornton PE, Running SW, White MA. Generating surfaces of daily meteorological variables over large regions of complex terrain. J Hydrol. 1997;190(3-4):214-51.

43. Masselot P, Chebana F, Lavigne É, Campagna C, Gosselin P, Ouarda TB. Toward an Improved Air Pollution Warning System in Quebec. Int J Environ Res Public Health. 2019:16(12):2095.

44. Yan B, Chebana F, Masselot P, Campagna C, Gosselin P, Ouarda TB, et al. A cold-health watch and warning system, applied to the province of Quebec (Canada). Sci Total Environ. 2020;741:140188.

45. Lee JY, Kim H. Projection of future temperature-related mortality due to climate and demographic changes. Environ Int. 2016;94:489-94.

46. Litvak E, Fortier I, Gouillou M, Jehanno A, Kosatsky T. Programme de vigie et de prévention des effets de la chaleur accablante à Montréal: Direction de santé publique Montréal; 2005.

47. Bhaskaran K, Gasparrini A, Hajat S, Smeeth L, Armstrong B. Time series regression studies in environmental epidemiology. Int J Epidemiol. 2013; 42(4):1187-95.

48. Guo Y, Gasparrini A, Armstrong BG, Tawatsupa B, Tobias A, Lavigne E, et al. Heat wave and mortality: a multicountry, multicommunity study. Environ Health Perspect. 2017;125(8):087006

49. Smith T, Zaitchik B, Gohlke J. Heat waves in the United States: definitions, patterns and trends. Clim Chang. 2013;118(3-4):811-25.

50. Yang J, Yin P, Sun J, Wang B, Zhou M, Li M, et al. Heatwave and mortality in 31 major Chinese cities: definition, vulnerability and implications. Sci Total Environ. 2019:649:695-702.

51. Chiu Y, Chebana F, Abdous B, Bélanger D, Gosselin P. Mortality and morbidity peaks modeling: An extreme value theory approach. Stat Methods Med Res. 2018;27(5):1498-512.

52. Lorenz EN. Atmospheric predictability experiments with a large numerical model. Tellus. 1982;34(6):505-13.

53. Gasparrini A, Armstrong B, Kenward MG. Distributed lag non-linear models. Stat Med. 2010;29(21):2224-34.

54. Gasparrini A, Scheipl F, Armstrong B, Kenward MG. A penalized framework for distributed lag non-linear models. Biometrics. 2017;73(3):938-48.

55. Gasparrini A, Guo Y, Hashizume M, Kinney PL, Petkova EP, Lavigne E, et al. Temporal variation in heat-mortality associations: a multicountry study. Environ Health Perspect. 2015;123(11):1200-7.

56. Sheridan SC, Lee CC, Allen MJ. The mortality response to absolute and relative temperature extremes. Int J Environ Res Public Health. 2019;16(9):1493.

57. Pascal M, Wagner $\mathrm{V}$, Le Tertre A, Laaidi K, Honoré C, Bénichou F, et al. Definition of temperature thresholds: the example of the French heat wave warning system. Int J Biometeorol. 2013;57(1):21-9.

58. Giroux J-X, Chebana F, Gosselin P, Bustinza R. Indicateurs et valeurs-seuils météorologiques pour les systèmes de veille-avertissement canicule pour le Québec. In: Mise à jour de l'étude de 2010 et développement d'un logiciel de calcul pour les systèmes d'alerte: INRS, Centre Eau Terre Environnement; 2017

59. Willett KM, Sherwood S. Exceedance of heat index thresholds for 15 regions under a warming climate using the wet-bulb globe temperature. Int Climatol. 2012;32(2):161-77.

60. Nairn JR, Fawcett RJ. The excess heat factor: a metric for heatwave intensity and its use in classifying heatwave severity. Int J Environ Res Public Health. 2015:12(1):227-53.

61. Jendritzky G, de Dear R, Havenith G. UTCl—why another thermal index? Int J Biometeorol. 2012:56(3):421-8.

62. Oleson K, Monaghan A, Wilhelmi O, Barlage M, Brunsell N, Feddema J, et al. Interactions between urbanization, heat stress, and climate change. Clim Chang. 2015;129(3-4):525-41

63. Valois P, Talbot D, Caron M, Carrier M-P, Morin AJ, Renaud J-S, et al. Development and validation of a behavioural index for adaptation to high summer temperatures among urban dwellers. Int J Environ Res Public Health. 2017;14(7):820 
64. Spagnolo J, De Dear R. A field study of thermal comfort in outdoor and semi-outdoor environments in subtropical Sydney Australia. Build Environ. 2003;38(5):721-38.

65. Vaneckova P, Neville G, Tippett V, Aitken P, FitzGerald G, Tong S. Do biometeorological indices improve modeling outcomes of heat-related mortality? J Appl Meteorol Climatol. 2011;50(6):1165-76.

66. Lin Y-K, Chang C-K, Li M-H, Wu Y-C, Wang Y-C. High-temperature indices associated with mortality and outpatient visits: characterizing the association with elevated temperature. Sci Total Environ. 2012;427:41-9.

67. Xu Z, Cheng J, Hu W, Tong S. Heatwave and health events: A systematic evaluation of different temperature indicators, heatwave intensities and durations. Sci Total Environ. 2018;630:679-89.

68. Valois P, Talbot D, Renaud J-S, Caron M, Carrier M-P. Développement d'un indice d'adaptation à la chaleur chez les personnes habitant dans les 10 villes les plus peuplées du Québec. Québec: Université Laval; 2016.

69. Goddard L, Mason SJ, Zebiak SE, Ropelewski CF, Basher R, Cane MA. Current approaches to seasonal to interannual climate predictions. Int J Climatol. 2001;21(9):1111-52.

70. Masterton, J.M. and F. Richardson, Humidex: a method of quantifying human discomfort due to excessive heat and humidity. 1979: Environment Canada, Atmospheric Environment.

71. Toloo G, FitzGerald G, Aitken P, Verrall K, Tong S. Evaluating the effectiveness of heat warning systems: systematic review of epidemiological evidence. Int J Public Health. 2013;58(5):667-81.

72. Barnett AG, Tong S, Clements AC. What measure of temperature is the best predictor of mortality? Environ Res. 2010;110(6):604-11.

73. Höppe $P$. The physiological equivalent temperature-a universal index for the biometeorological assessment of the thermal environment. Int J Biometeorol. 1999;43(2):71-5.

74. Besancenot J-P. Vagues de chaleur et mortalité dans les grandes agglomérations urbaines. Environ Risques Santé. 2002;1 (4):229-40.

75. Armstrong B, Sera F, Vicedo-Cabrera AM, Abrutzky R, Åström DO, Bell ML, et al. The role of humidity in associations of high temperature with mortality: a multicountry, multicity study. Environ Health Perspect. 2019;127(9):097007.

\section{Publisher's Note}

Springer Nature remains neutral with regard to jurisdictional claims in published maps and institutional affiliations.

Ready to submit your research? Choose BMC and benefit from:

- fast, convenient online submission

- thorough peer review by experienced researchers in your field

- rapid publication on acceptance

- support for research data, including large and complex data types

- gold Open Access which fosters wider collaboration and increased citations

- maximum visibility for your research: over $100 \mathrm{M}$ website views per year

At $\mathrm{BMC}$, research is always in progress.

Learn more biomedcentral.com/submissions 